Shigeo Kure • Toshikatsu Shinka • Yoshiyuki Sakata

Narasaki Osamu • Masaru Takayanagi $\cdot$ Keiya Tada

Yoichi Matsubara $\cdot$ Kuniaki Narisawa

\title{
A one-base deletion (183delC) and a missense mutation (D276H) in the T-protein gene from a Japanese family with nonketotic hyperglycinemia
}

\begin{abstract}
Two novel mutations in the gene encoding Tprotein, a component of the glycine cleavage system, were identified in a Japanese family with nonketotic hyperglycinemia. The proband had two affected sibs, and enzymatic analysis of the liver sample from the proband revealed the T-protein deficiency. The first mutation, $183 \mathrm{delC}$, was found in exon 1 . One of six cytidine residues (base position 183-188) was deleted. The deletion was located in a coding region of the mitochondrial leader peptide and was deduced to create a truncated peptide with 94 amino acids. The second mutation was a base substitution from $\mathrm{G}$ to $\mathrm{C}$ at position 955 in exon 7. The G955C substitution caused an amino acid change from aspartate to histidine at position $276(\mathrm{D} 276 \mathrm{H})$. Aspartic acid at position 276 is evolutionarily conserved among human, bovine, chicken, and pea genes, and replaced by glutamic acid in Escherichia coli, suggesting that the presence of an acidic amino acid at 276 may be crucial for the enzymatic function. No base change other than the $183 \mathrm{delC}$ and the G955C was observed in the sequencing analysis. Familial analysis revealed that the $183 \mathrm{delC}$ and the $\mathrm{D} 276 \mathrm{H}$ mutations were inherited from the father and the mother, respectively. This is the first report of T-protein gene mutation in Oriental patients with nonketotic hyperglycinemia.
\end{abstract}

Key words Nonketotic hyperglycinemia $\cdot$ T-protein gene Japanese patient $\cdot$ Compound heterozygosity $\cdot$ One-base deletion

\footnotetext{
S. Kure $(\bowtie) \cdot$ T. Shinka $\cdot$ Y. Sakata $\cdot$ M. Takayanagi $\cdot$ Y. Matsubara K. Narisawa

Department of Biochemical Genetics, Tohoku University School of Medicine, 1-1 Seiryomachi, Aobaku, 980-8574 Sendai, Japan

Tel. +81-22-717-8140; Fax +81-22-717-8142

e-mail: skure@mail.cc.tohoku.ac.jp

N. Osamu

Department of Pediatrics, Fukuoka City Children's Hospital,

Fukuoka, Japan

K. Tada

NTT Tohoku Hospital, Sendai, Japan
}

\section{Introduction}

Nonketotic hyperglycinemia (NKH) is an inborn error of metabolism inherited as an autosomal recessive trait, and characterized by accumulation of a large amount of glycine in body fluid and by severe neurological symptoms (Tada and Hayasaka 1987). The fundamental defect lies in the mitochondrial glycine cleavage system (GCS) (Tada et al. 1969). The GCS consists of four individual constituents, referred to as P-, H-, T-, and L-protein. Enzymatic analysis revealed that most patients with NKH were deficient in Pprotein activity, while the rest of the patients had reduced T-protein (aminomethyltransferase; EC 2.1.2.10) activity. Several mutations in the P-protein gene have been identified (Kure et al. 1991, 1992). The gene encoding human Tprotein, officially designated as the aminomethyltransferase $(A M T)$ gene, is located on chromosome $3 \mathrm{p} 12$, organized in 9 exons, and spans $6 \mathrm{~kb}$ (Nanao et al. 1994a). Four mutations in the T-protein gene have been reported to date. All of them were missense mutations found in Caucasian patients with NKH (Nanao et al. 1994b, Kure et al. 1998). We present here two novel mutations, a one-base deletion and a missense mutation, in the T-protein gene, found in a Japanese family with neonatal onset of NKH.

\section{Patients and methods}

Patients

A proband (II-3 in Fig. 1a) was born as one of the identical twins from nonconsanguineous parents. He was admitted to neonatal care unit at 2 days of age because of hypotonia and respiratory failure. Glycine concentrations in the cerebrospinal fluid and serum were 73.5 and $213.3 \mathrm{nmol} / \mathrm{ml}$, respectively, giving the ratio of 0.34 (normal range, less than 0.09). His sister (II-1) and twin brother (II-2) presented symptoms similar to those of the proband. The overall GCS activity in the biopsied liver sample from the proband was 0.01 nmole per milligram of protein per hour (normal 


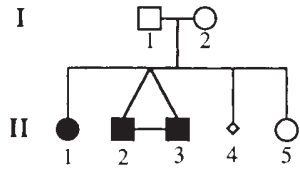

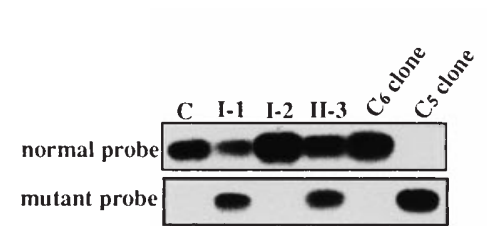

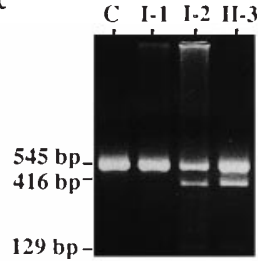

Fig. 1 T-protein gene mutations in a Japanese family with NKH. a The pedigree of the family. The proband was II-3. A small diamond indicates a spontaneously aborted fetus. b Detection of the 183 delC mutation by allele-specific oligonucleotide hybridization (ASO). The DNA fragments containing exons 1 and 2 were amplified from DNA of a control subject $(C)$, the selected family members $(I-1, I-2$, and $I I-3)$, a plasmid clone with the normal exon 1 sequence $\left(C_{6}\right.$ clone $)$, and a clone with the $183 \mathrm{delC}$ mutation $\left(C_{5}\right.$ clone $)$. The hybridization profiles with the normal and mutant ASO probes were visualized by autoradiography. c Detection of the D276H mutation by HinfI digestion. The DNA fragments $(545 \mathrm{bp})$ containing exons 6 and 7 were amplified by PCR from the genomic DNA of a control subject $(C)$, and three family members $(I-1, I-2$, and $I I-3)$. The HinfI digestion of the polymerase chain reaction (PCR) products from the $\mathrm{D} 276 \mathrm{H}$ allele generated two DNA fragments of 416 and $129 \mathrm{bp}$. The 129-bp band is hardly visible under these conditions range 1-11.0). $\mathrm{P}$ - and T-protein activities were 19.2 (5.0-20) and 0 (48-102) nmole per milligram of protein per hour, respectively, suggesting that the patient had a defect in the $\mathrm{T}$-protein gene.

\section{Sequencing and detection of mutations}

High molecular weight DNAs were prepared from the blood samples from the proband and the parents by proteinase $\mathrm{K}$ digestion and phenol extraction. A genomic fragment containing exons 1 and 2 was amplified by polymerase chain reaction (PCR) with primers of TE1-2F, 5' TGCGCCGTCTGCACTCGTTG-3' and TE1-2R, 5'ACAGCAAACAAAGCCAAGGAGTG-3'. A DNA fragment that contained exons 6 and 7 was amplified with TE6-7-F, 5' -CTGGATACTTGGTCACTGGCTCC-3' and TE6-7R, 5'-GAGTCATGGGCTGGCTAGTCTTA-3'. The primers were designed based on the sequence data obtained from GenBank D14681 and D14685. The thermoprofile of the PCR was $10 \mathrm{~s}$ at $98^{\circ} \mathrm{C}, 30 \mathrm{~s}$ at $55^{\circ} \mathrm{C}$, and $30 \mathrm{~s}$ at $72^{\circ} \mathrm{C}$ for 35 cycles. For the amplification of exons 1 and $2,10 \%$ dimethylsulfoxide was added to the PCR mixture.

The amplified DNA fragments of exons 1 and 2 were cloned into the plasmid vector Bluescript (Stratagene, La Jolla, CA, USA) and sequenced, while the DNA fragments of exons 6 and 7 were subjected to direct sequence analysis. Allele specific oligonucleotide hybridization (ASO) was used for detection of $183 \mathrm{delC}$. The DNA fragment containing exons 1 and 2 was subjected to $2.5 \%$ agarose gel electrophoresis and transferred to a nylon membrane. The nucleotide sequences of the normal and mutant ASO probes were 5'-GCATTCCCCCCGGCCTT-3' and 5'GCATTCCCCCGGCCTTG-3', respectively. Labeling of the probes and the conditions for hybridization and washing were previously reported (Kure et al. 1992). The D276H mutation was detected by HinfI digestion. The DNA fragments containing exon 7 were amplified and the HinfI digestion was performed at $37^{\circ} \mathrm{C}$ overnight in $20 \mu \mathrm{l}$ of reaction mixture which contained $10 \mu \mathrm{l}$ of the PCR product and 10 units of the enzyme. The digested fragments were separated by $2.5 \%$ agarose gel electrophoresis and stained with ethidium bromide.
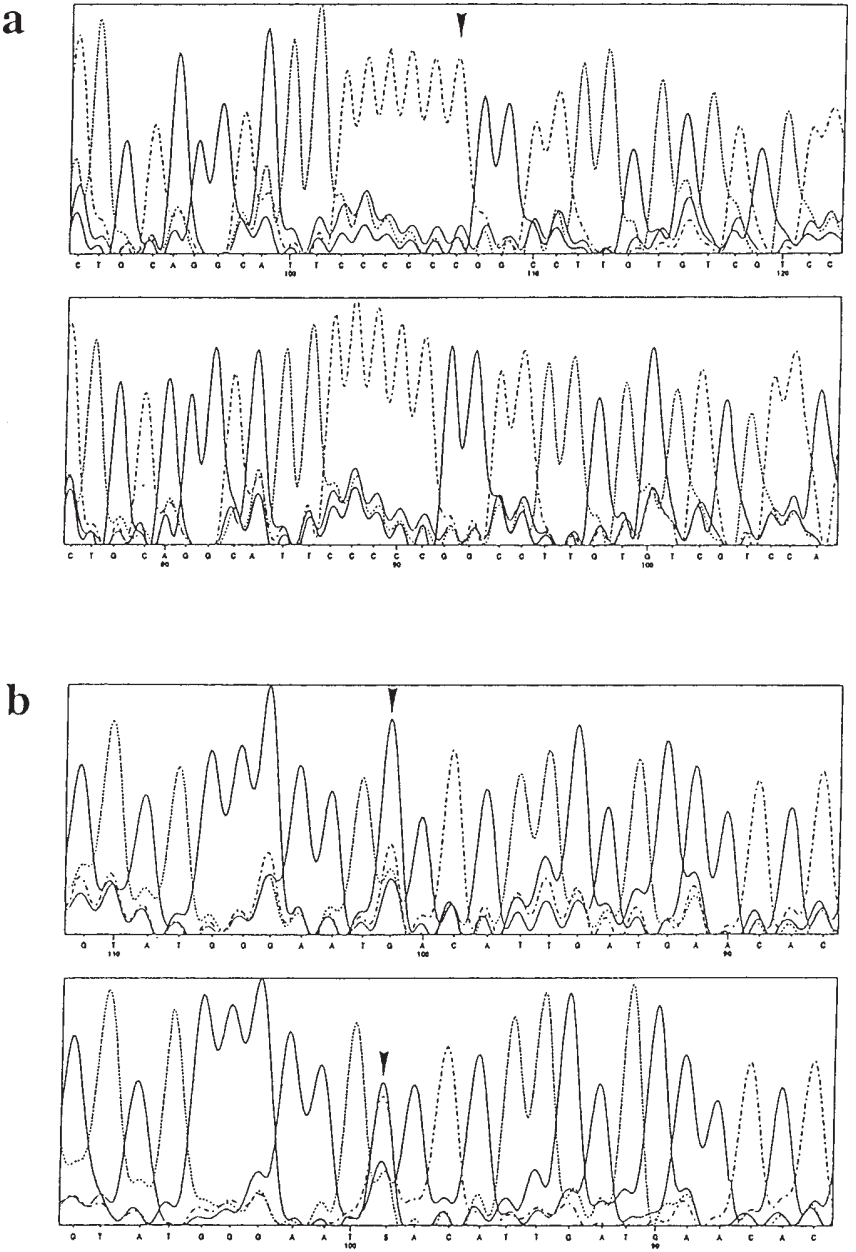

Fig. 2 a Sequence analysis of the 183 delC mutation. The upper and lower panels show a clone with the normal exon 1 sequence and a clone with the $183 \mathrm{delC}$ mutation, respectively. The arrow indicates the nucleotide at position 188. b Direct sequence analysis of the D276H mutation. The arrow indicates the nucleotide at position 955. The normal sequence (upper panel) and the sequence with the $\mathrm{D} 276 \mathrm{H}$ mutation (lower panel) are shown 


\section{Results and discussion}

\section{3delC}

Deletion of a cystidine residue was detected in exon 1 of the T-protein gene. The genomic DNA fragment containing exons 1 and 2 was amplified by PCR with a pair of primers, TE1-2F and TE1-2R. The PCR product was cloned into the plasmid vector and a total of 10 clones were analyzed. One of six cytidines from position 183 to 188 was deleted in 8 clones, but not deleted in 2 clones (Fig. 2a). The one-base deletion was further confirmed by the ASO hybridization analysis (Fig. 1b). Both normal and mutant types of oligonucleotide probes were hybridized with the DNA fragments amplified from the proband and his father, while only the normal type probe was hybridized with the fragments from a control subject and the proband's mother. This suggests that the proband inherited the deletion from his father. The mutation was located in a coding region of the mitochondrial leader peptide and was deduced to create a truncated polypeptide with 94 amino acids. Since the truncated polypeptide shares no common peptide with the mature T-protein, the mutant enzyme should have no residual activity.

\section{D276H}

A heterozygous base substitution from $\mathrm{G}$ to $\mathrm{C}$ at position 955 was detected in exon 7 (Fig. 2b). No base change other than $\mathrm{G} 955 \mathrm{C}$ or $183 \mathrm{delC}$ was observed in the sequencing analysis of the patient II-3. The G955C substitution was deduced to cause an amino acid change from aspartate to histidine at position $276(\mathrm{D} 276 \mathrm{H})$, and to create a recognition site for HinfI (GAATC). The DNA fragments amplified from the DNA samples of the proband and his mother were partially digested with HinfI, indicating that he and his mother carried the $\mathrm{D} 276 \mathrm{H}$ mutation in a heterozygous form
(Fig. 1c). The D276H mutation has not been reported previously. We examined 50 control Japanese subjects by this method and found no D276H mutant allele. Aspartic acid at position 276 is evolutionarily conserved among human, bovine, chicken, and pea genes, and replaced by glutamic acid in Escherichia coli (Okamura-Ikeda et al. 1993), suggesting that the presence of an acidic amino acid at 276 may be critical for the enzymatic function of T-protein. Since the liver specimen from the proband had no residual activity of the T-protein, the D276H mutation as well as the $183 \mathrm{delC}$ mutation may be a null mutation.

\section{References}

Kure S, Narisawa K, Tada K (1991) Structural and expression analyses of normal and mutant mRNA encoding glycine decarboxylase: Three-base deletion in mRNA causes nonketotic hyperglycinemia. Biochem Biophys Res Commun 174: 1176-1182

Kure S, Takayanagi M, Narisawa K, Tada K, Leisti J (1992) Identification of a common mutation in Finnish patients with nonketotic hyperglycinemia. J Clin Invest 90: 160-164

Kure S, Mandel H, Rolland MO, Sakata Y, Shinka T, Drugan A, Boneh A, Tada K, Matsubara Y, Narisawa K (1998) A missense mutation (His42Arg) in the T-protein gene from a large Israeli-Arab kindred with nonketotic hyperglycinemia. Hum Genet (in press)

Nanao K, Takada G, Takahashi E, Seki N, Komatsu Y, OkamuraIkeda K, Motokawa Y, Hayasaka K (1994a) Structure and chromosomal localization of the aminomethyltransferase gene (AMT). Genomics 19: 27-30

Nanao K, Okamura-Ikeda K, Motokawa Y, Danks DM, Baumgartner ER, Takada G, Hayasaka K (1994b) Identification of the mutations in the T-protein gene causing typical and atypical nonketotic hyperglycinemia. Hum Genet 93: 655-658

Okamura-Ikeda K, Ohmura Y, Fujiwara K, Motokawa Y (1993) Cloning and nucleotide sequence of the gcv operon encoding the Escherichia coli glycine cleavage system. Eur J Biochem 216: 539548

Tada K, Narisawa K, Yoshida T, Yokoyama K, Nakagawa H, Tanno K, Mochizuki K, Arakawa T (1969) Hyperglycinemia: a defect in glycine cleavage reaction. Tohoku J Exp Med 98: 289-296

Tada K, Hayasaka K (1987) Non-ketotic hyperglycinaemia: clinical and biochemical aspects. Eur J Pediatr 146: 221-227 